\title{
Matriz de contabilidade social, resultado primário e pagamento de juros por setor institucional no Brasil*
}

\author{
Social accounting matrix, net lending and interest payment by \\ institutional sector in Brazil
}

Lucas Vasconcelos e Nelson Henrique Barbosa-Filho**

\begin{abstract}
Resumo: Este trabalho apresenta a distribuição da renda, do gasto e do financiamento dos principais agentes da economia brasileira, bem como o padrão de aquisição de seus ativos financeiros, a partir da construção de uma Matriz de Contabilidade Social (SAM) Vertical para o Brasil, conforme proposto por Barbosa-Filho (2018). Essa matriz permite a exploração de diversas linhas analíticas envolvendo as principais variáveis econômicas de fluxo e estoque, mostrando-se um instrumento de ensino e pesquisa em economia simples e intuitivo. Descrevemos a estrutura da SAM vertical brasileira para o ano de 2016 e analisamos o padrão de pagamento de juros entre os agentes econômicos e o comportamento do resultado primário dos setores institucionais ao longo do período 2000-16.
\end{abstract}

Palavras-chave: Matriz de Contabilidade Social; Economia Brasileira; Resultado Primário e Pagamento de Juros

\begin{abstract}
This paper presents the distribution of income, expenditure, and financing of the main agents of the Brazilian economy, as well as the pattern of acquisition of its financial assets, based on the construction of a Vertical Social Accounting Matrix (SAM) for Brazil, as proposed by Barbosa-Filho (2018). This matrix allows the exploration of several analytical frames involving the central stock and flow economic variables, showing itself as a simple and intuitive instrument of teaching and research in economics. We describe the structure of the Brazilian vertical SAM for 2016 and analyze the patterns of interest payment among economic agents and net lending of the institutional sectors throughout 2000-16.
\end{abstract}

Keywords: Social Accounting Matrix; Brazilian Economy; Net Lending and Interest Payments

JEL: E16; N16; A2

\footnotetext{
* Submissão: 21/08/2020 | Aprovação: 06/12/2020 | DOI: 10.5380/re.v42i77.75981

** Respectivamente: (1) Pesquisador do IPEA e doutorando em Economia Política na UnB | E-mail: ferraz.vasconcelos@gmail.com | ORCID: 0000-0001-6703-836X | (2) Professor da EESP/FGV e da UnB | E-mail: nelson.barbosa@ fgv.br | ORCID: 0000-0003-3889-5703
} 


\section{Introdução}

A desagregação de dados macroeconômicos por setor institucional permite a análise da distribuição de renda, gasto e financiamento entre os principais agentes de uma economia. Este tipo de análise reflete o conceito pioneiro de Matriz de Contabilidade Social (Stone e Brown, 1962), que por sua vez é utilizado como base para modelos estruturalistas (Taylor, 1990) e pós-keynesianos (Godley e Lavoie, 2012) de crescimento e distribuição de renda.

Com maior acesso a dados, o conceito de Matriz de Contabilidade Social foi incorporado definitivamente ao Sistema de Contas Nacionais das Nações Unidas nas últimas décadas na forma das Contas Econômicas Integradas (CEI). No Brasil, este tipo de informação é publicado pelo Instituto Brasileiro de Geografia e Estatística (IBGE) desde 2000. Nos Estados Unidos, o Bureau of Economic Analysis começou a fazer o mesmo a partir de 2006.

Do ponto de vista metodológico, as CEI incluem toda a informação necessária para analisar padrões de renda, gasto e financiamento. Porém, sua estrutura contábil não é muito amigável ao usuário, o que dificulta sua utilização generalizada em modelos macroeconômicos. Para suprir esta lacuna, BarbosaFilho (2018) apresentou uma versão resumida e "vertical" das CEI dos Estados Unidos, mostrando a composição sequencial da renda, da produção à demanda, bem como a distribuição dos desequilíbrios correntes e a acumulação de ativos financeiros líquidos por setor institucional. Adotando uma metodologia similar à de Godley e Lavoie (2012), Macedo e Silva e dos Santos (2016) e dos Santos (2017) analisaram a estrutura do sistema financeiro brasileiro.

Este artigo tem por objetivo aplicar a metodologia proposta por BarbosaFilho (2018) ao Brasil e utilizar os dados resultantes para analisar a evolução recente do pagamento de juros e do resultado primário dos cinco principais setores institucionais da economia brasileira.

O texto está organizado em cinco seções incluindo esta introdução. A segunda seção aplica o conceito de matriz de contabilidade social "vertical" proposto por Barbosa-Filho (2018) ao Brasil. A terceira faz o mesmo para a matriz de fluxo de fundos e de ativos financeiros líquidos. A quarta utiliza os dados do IBGE para avaliar os resultados financeiro e primário de cada agente institucional, bem como os pagamentos de juros líquidos entre esses agentes. A última seção 
conclui a análise com observações sobre a interação entre governo e os demais setores institucionais da economia brasileira.

\section{A Matriz de Contabilidade Social Vertical do Brasil}

Os dados da SAM vertical são organizados a partir de seis setores institucionais: Famílias (FAM), Empresas não financeiras (EMP) ${ }^{1}$, Empresas financeiras (FIN) ${ }^{2}$, Governo Geral (GOV), Instituições sem fins de lucro a serviço das famílias (ISL) e Resto do mundo (RDM). O setor Governo Geral inclui as administrações federal, estadual e municipal, mas as empresas estatais fazem parte do setor empresarial. O Resto do mundo representa todos os agentes não residentes que interagem com os residentes.

Como ressaltado por Barbosa-Filho (2018), o ponto de partida da SAM vertical é a definição do Produto Interno Bruto (PIB), reescrita em termos de oferta (valor adicionado mais importações) e demanda (absorção doméstica mais exportações) agregadas para representar os setores institucionais, tal como mostrado na equação 1 .

$$
P_{Y} Y+e P_{M} M=P_{C} C+P_{I} I+P_{X} X
$$

onde $P_{i}$ equivale ao índice de preço da variável real $i$, que pode representar o PIB $(Y)$, as importações $(M)$, o consumo $(C)$, o investimento $(I)$ e as exportações $(X)$. A taxa de câmbio nominal $e$ diz respeito ao preço doméstico da moeda externa, e $P_{M}$ é o preço das importações em moeda externa.

Pelo lado da demanda, pode haver consumo por parte de três setores institucionais (Famílias, Governo e Instituições sem fins lucrativos) e investimento, de cinco setores institucionais (Famílias, Empresas não financeiras, Empresas financeiras, Governo e Instituições sem fins lucrativos). Desta forma, a parte direita da equação desdobra-se em

$$
\begin{aligned}
& P_{Y} Y+e P_{M} M= \\
& P_{C}\left(C_{F A M}+C_{G O V}+C_{I S L}\right)+ \\
& P_{I}\left(I_{F A M}+I_{E M P}+I_{F I N}+I_{G O V}+I_{I S L}\right)+P_{X} X
\end{aligned}
$$

\footnotetext{
${ }^{1}$ Empresas públicas não financeiras fazem parte deste setor institucional.

${ }^{2}$ As instituições financeiras incluem o Banco Central e os bancos públicos.
} 
onde $C_{j}$ e $I_{j}$ representam consumo, e investimento reais do setor institucional $j$.

Por sua vez, a desagregação do lado esquerdo da equação 2 expressa a renda final disponível para cada setor institucional. Inicialmente, a renda de cada setor institucional é o valor que ele adiciona aos insumos intermediários. Quanto ao setor Resto do mundo, sua renda inicial são as importações. Para completar o quadro, é preciso adicionar os impostos líquidos indiretos à oferta agregada nominal referente ao Governo. A soma destes componentes resulta no PIB a preços de mercado. Essa desagregação é mostrada na equação 3. Para se obter a renda disponível de cada setor, é necessário analisar a realocação da renda entre os setores institucionais devido aos fluxos de juros, dividendos, impostos, benefícios etc., que é uma das partes fundamentais da SAM vertical.

$$
\begin{gathered}
P_{F A M} Y_{F A M}+P_{E M P} Y_{E M P}+P_{F I N} Y_{F I N}+P_{G O V} Y_{G O V}+P_{I S L} Y_{I S L}+e P_{M} M+T= \\
P_{C}\left(C_{F A M}+C_{G O V}+C_{I S L}\right)+P_{I}\left(I_{F A M}+I_{E M P}+I_{F I N}+I_{G O V}+I_{I S L}\right)+P_{X} X
\end{gathered}
$$

onde $Y_{j}$ é o valor adicionado real por setor $j$ e $T$ representa os impostos indiretos menos os subsídios em termos nominais.

A Tabela 1 mostra os dados correspondentes ao lado esquerdo da equação 3 para a economia brasileira no ano de 2016. A oferta total foi de $\mathrm{R} \$ 7$ trilhões, sendo que 89,2\% desse valor provieram de fontes internas (PIB), e o restante, do setor externo (importações). Os principais componentes do valor adicionado detalham as rendas primárias, que são as "rendas que se revertem para as unidades institucionais como resultado de sua participação no processo de produção ou pela propriedade de ativos necessários à produção", ou seja, constituem a renda gerada no processo de produção que é distribuída entre os fatores (capital e trabalho) e as administrações públicas (IBGE, 2016). 
Tabela 1 - Brasil, 2016, fluxos de renda iniciais por setor institucional em milhões de reais, recebimentos (+) ou pagamentos (-)

\begin{tabular}{|c|c|c|c|c|c|c|c|}
\hline & FAM & EMP & FIN & GOV & ISL & RDM & Total \\
\hline $\begin{array}{l}\text { 1) Valor } \\
\text { adicionado PM + } \\
\text { importações }\end{array}$ & 1.142 .389 & 2.798.175 & 416.253 & 1.855 .333 & 55.055 & 756.520 & 7.023 .725 \\
\hline $\begin{array}{l}\text { Remuneração de } \\
\text { empregados }\end{array}$ & 133.462 & 1.614 .413 & 156.672 & 847.005 & 50.884 & & 2.802 .436 \\
\hline Salários & 127.852 & 1.286 .726 & 120.761 & 651.859 & 42.094 & & \\
\hline $\begin{array}{l}\text { Contribuições } \\
\text { sociais }\end{array}$ & 5.610 & 327.687 & 35.911 & 195.146 & 8.790 & & \\
\hline $\begin{array}{l}\text { Contribuições } \\
\text { sociais efetivas }\end{array}$ & 5.610 & 327.687 & 35.911 & 116.801 & 8.790 & & \\
\hline $\begin{array}{l}\text { Contribuições } \\
\text { sociais efetivas } \\
\text { imputadas }\end{array}$ & & & & 78.345 & & & \\
\hline $\begin{array}{l}\text { Rendimento } \\
\text { misto }\end{array}$ & 528.348 & & & & & & 528.348 \\
\hline $\begin{array}{l}\text { Excedente } \\
\text { operacional bruto } \\
\text { Impostos líquidos }\end{array}$ & 480.579 & 1.183 .762 & 259.581 & 97.958 & 4.171 & & 2.026 .051 \\
\hline $\begin{array}{l}\text { sobre o produto e } \\
\text { a produção }\end{array}$ & & & & 910.370 & & & 910.370 \\
\hline Importação & & & & & & 756.520 & 756.520 \\
\hline Total (\%) & $16,3 \%$ & $39,8 \%$ & $5,9 \%$ & $26,4 \%$ & $0,8 \%$ & $10,8 \%$ & $100 \%$ \\
\hline
\end{tabular}

Fonte: Contas Econômicas Integradas, 2016. Elaboração dos autores.

Nota-se que a maior parte da remuneração dos empregados originou-se nas empresas não financeiras e no governo. Quase $80 \%$ dessa remuneração referem-se aos salários, enquanto o restante diz respeito às contribuições sociais. Como todos os setores institucionais domésticos realizaram investimento, todos possuíam renda advinda do excedente operacional bruto, porém mais de $50 \%$ desse valor foi concentrado nas empresas não financeiras. Quanto ao rendimento misto bruto ${ }^{3}$, ele foi registrado como renda das famílias, totalizando $\mathrm{R} \$ 528,4$ bilhões. Por fím, os impostos indiretos foram destinados integralmente ao governo, e todas as importações, para o resto do mundo.

As empresas não financeiras produziram grande parte da oferta total a preços de mercado $(39,8 \%)$, seguida pelo governo $(26,4 \%)$, pelas famílias $(16,3 \%)$, pelo resto

\footnotetext{
${ }^{3} \mathrm{O}$ rendimento misto bruto é a "remuneração recebida pelos proprietários de empresas não constituídas em sociedade (autônomos), que não pode ser identificada separadamente se proveniente do capital ou do trabalho" (IBGE, 2016).
} 
do mundo (10,8\%), pelas empresas financeiras $(5,9 \%)$ e, finalmente, pelas instituições sem fins lucrativos $(0,8 \%)$. Comparando com os dados apresentados por BarbosaFilho (2018) para os Estados Unidos em 2015, observa-se que o setor empresarial e o resto do mundo responderam por uma parcela maior da oferta total naquele país: $63,9 \%$ e 13,4\%, respectivamente; enquanto no Brasil as empresas financeiras e não financeiras equivalem a 45,8\%, e o resto do mundo, a 10,8\%. Por outro lado, a participação do governo e das famílias (inclusive ISL) foi significativamente maior no Brasil: 26,4\% e 17\%, respectivamente, contra 16,3\% e 6,4\% nos Estados Unidos.

Prosseguindo na análise para além da renda primária, a remuneração dos empregados foi integralmente transferida para as famílias, e parte do excedente operacional, redistribuído na forma de juros, dividendos e outras formas de ativos, como mostrado na Tabela 2.

Tabela 2 - Brasil, 2016, realocação das rendas do trabalho e de propriedade por setor institucional em milhões de reais, recebimentos (+) ou pagamentos (-)

\begin{tabular}{|c|c|c|c|c|c|c|c|}
\hline & FAM & EMP & FIN & GOV & ISL & RDM & Total \\
\hline $\begin{array}{l}\text { 1) Valor adicionado PM } \\
+ \text { importações }\end{array}$ & 1.142 .389 & 2.798.175 & 416.253 & 1.855 .333 & 55.055 & 756.520 & 7.023.725 \\
\hline $\begin{array}{l}\text { 2) Realocação da renda } \\
\text { do trabalho }\end{array}$ & 2.669 .981 & -1.614 .413 & -156.672 & -847.005 & -50.884 & -1.007 & $\mathbf{0}$ \\
\hline $\begin{array}{l}\text { Renda do trabalho } \\
\text { recebida de residentes }\end{array}$ & 2.668 .974 & -1.614 .413 & -156.672 & -847.005 & -50.884 & & 0 \\
\hline $\begin{array}{l}\text { Renda do trabalho paga a } \\
\text { não residentes }\end{array}$ & -294 & & & & & 294 & 0 \\
\hline $\begin{array}{l}\text { Renda do trabalho } \\
\text { recebida de não residentes }\end{array}$ & 1.301 & & & & & -1.301 & 0 \\
\hline $\begin{array}{l}\text { 3) Realocação da renda } \\
\text { de propriedade }\end{array}$ & 526.579 & -387.887 & -44.499 & -232.948 & 7.035 & 131.720 & $\mathbf{0}$ \\
\hline Juros & 95.558 & -10.251 & 128.241 & -285.007 & 6.959 & 64.500 & 0 \\
\hline Dividendos e Retiradas & 344.270 & -314.426 & -73.786 & 4.368 & & 39.574 & 0 \\
\hline Lucros reinvestidos & & -25.980 & -1.638 & & & 27.618 & 0 \\
\hline $\begin{array}{l}\text { Rendimentos de } \\
\text { investimentos }\end{array}$ & 87.702 & 7.998 & -97.316 & 1.512 & 76 & 28 & 0 \\
\hline $\begin{array}{l}\text { Rendimentos de recursos } \\
\text { naturais }\end{array}$ & -951 & -45.228 & & 46.179 & & & 0 \\
\hline $\begin{array}{l}\text { 4) Renda Nacional Bruta } \\
+ \text { Importações }(1+2+3)\end{array}$ & 4.338.949 & 795.875 & 215.082 & 775.380 & 11.206 & 887.233 & 7.023.725 \\
\hline
\end{tabular}

Fonte: Contas Econômicas Integradas, 2016. Elaboração dos autores. 
Toda a remuneração do trabalho paga pelas empresas não financeiras ( $R$ \$ $1.614,4$ bilhões), empresas financeiras ( $\mathrm{R} \$ 156,7$ bilhões), governo ( $\mathrm{R} \$ 847$ bilhões) e instituições sem fins lucrativos ( $\mathrm{R}$ \$ 50,9 bilhões) foi realocada para as famílias. O balanço entre renda paga a residentes e recebida dos mesmos completou a realocação da renda do trabalho, totalizando $\mathrm{R}$ \$ 2,7 trilhões de renda para as famílias, conforme mostrado no item (2) da Tabela 2.

Quanto à realocação da renda de propriedade, o governo pagou $\mathrm{R} \$ 285$ bilhões, e as empresas não financeiras, $\mathrm{R} \$ 10,3$ bilhões de juros para todos os outros setores institucionais, cujas empresas financeiras receberam $\mathrm{R} \$ 128,2$ bilhões, as famílias, $\mathrm{R} \$ 95,6$ bilhões, o resto do mundo, $\mathrm{R} \$$ 64,5 bilhões e as instituições sem fins lucrativos, R\$ 7 bilhões. Os dividendos, em geral, são pagos pelas empresas financeiras e não financeiras aos outros setores institucionais. Essas empresas também enviaram lucros ao exterior no montante de R $\$ 27,6$ bilhões. Os rendimentos de investimentos foram recebidos por todos os setores institucionais, cuja origem dos recursos foram as empresas financeiras ( $R$ \$ 97,3 bilhões). Por fim, os rendimentos de recursos naturais foram pagos ao governo pelas famílias e empresas não financeiras. Em termos agregados, a realocação de renda de propriedade se deu das empresas (financeiras e não financeiras) e governo para as famílias (inclusive ISL) e resto do mundo.

Como o pagamento de um setor corresponde ao recebimento de outro em todos os fluxos de renda dos fatores realocados, a soma desses fluxos é sempre zero na última coluna da Tabela 2 . O valor total da soma da renda inicial dos setores institucionais permaneceu o mesmo ( $\mathrm{R} \$ 7$ trilhões), mas sua composição mudou significativamente. Por exemplo, a renda inicial das famílias, que era de $\mathrm{R}$ \$ 1,1 trilhão, proveniente da produção, passou a ser $\mathrm{R} \$ 4,3$ trilhões após a realocação de renda do trabalho e da propriedade. O resto do mundo também elevou sua renda após a realocação. Os setores restantes foram pagadores líquidos.

A terceira etapa da análise consiste na incorporação dos impostos e transferências, subtraindo os pagamentos de impostos diretos e contribuições sociais dos setores privados e adicionando estes recursos ao governo. Por outro lado, adiciona-se os benefícios sociais aos setores privados ao mesmo tempo em que são subtraídos do governo. A Tabela 3 mostra a realocação destes fluxos no Brasil para 2016. 
Tabela 3 - Brasil, 2016, impostos, contribuições sociais, benefícios sociais e outras transferências correntes por setor institucional em milhões de reais, recebimentos (+) ou pagamentos (-)

\begin{tabular}{|c|c|c|c|c|c|c|c|}
\hline & FAM & EMP & FIN & GOV & ISL & RDM & Total \\
\hline $\begin{array}{l}\text { 1) Valor adicionado } \\
\text { PM + importações }\end{array}$ & 1.142.389 & 2.798.175 & 416.253 & 1.855 .333 & 55.055 & 756.520 & 7.023.725 \\
\hline $\begin{array}{l}\text { 2) Realocação da } \\
\text { renda do trabalho }\end{array}$ & 2.669 .981 & -1.614 .413 & -156.672 & -847.005 & -50.884 & -1.007 & $\mathbf{0}$ \\
\hline $\begin{array}{l}\text { 3) Realocação da } \\
\text { renda de propriedade }\end{array}$ & 526.579 & -387.887 & -44.499 & -232.948 & 7.035 & 131.720 & $\mathbf{0}$ \\
\hline $\begin{array}{l}\text { 4) Renda Nacional } \\
\text { Bruta + Importações } \\
(1+2+3)\end{array}$ & 4.338.949 & 795.875 & 215.082 & 775.380 & 11.206 & 887.233 & 7.023.725 \\
\hline $\begin{array}{l}\text { 5) Impostos, } \\
\text { Contribuições e } \\
\text { Transferências }\end{array}$ & 65.016 & -328.299 & -13.732 & 205.856 & 80.339 & -9.180 & $\mathbf{0}$ \\
\hline Impostos diretos & -207.418 & -280.584 & -38.708 & 527.247 & -537 & & 0 \\
\hline Contribuições sociais & -787.092 & & 98.843 & 688.249 & & & 0 \\
\hline Benefícios sociais & 1.123 .676 & & -60.693 & -1.062 .983 & & & 0 \\
\hline $\begin{array}{l}\text { Outras transferências } \\
\text { líquidas recebidas }\end{array}$ & -64.150 & -47.715 & -13.174 & 53.343 & 80.876 & -9.180 & 0 \\
\hline $\begin{array}{l}\text { 6) Renda Disponível } \\
\text { Bruta + Importações } \\
(4+5)\end{array}$ & 4.403.965 & 467.576 & 201.350 & 981.236 & 91.545 & 878.053 & 7.023.725 \\
\hline
\end{tabular}

Fonte: Contas Econômicas Integradas (2016). Elaboração dos autores.

O governo recebeu $R \$ 527,3$ bilhões em impostos diretos, sendo que a maior parte destes recursos vieram das empresas não financeiras e das famílias, enquanto os $\mathrm{R} \$ 688,3$ bilhões recebidos pelo governo de contribuições sociais tiveram origem no setor famílias. Por seu turno, o governo pagou R 1 trilhão em benefícios sociais às famílias, valor que foi complementado pelo pagamento adicional às famílias de $\mathrm{R} \$ 60,7$ bilhões em benefícios sociais por parte das empresas financeiras. Por fim, outras transferências aumentaram a renda líquida do governo e das ISL em $\mathrm{R} \$ 53,3$ bilhões e $\mathrm{R} \$ 80,9$ bilhões, respectivamente. Os recursos vieram das famílias, das empresas financeiras e não financeiras e do resto do mundo.

A Tabela 3 mostra a renda final de cada setor institucional, ou seja, a renda disponível para o dispêndio em consumo, investimento e, no caso do resto do mundo, exportações. A renda final é igual à oferta ou demanda agregadas, e sua composição é primordial para a mensuração dos saldos financeiros de cada setor 
institucional. A realocação da renda dos fatores, impostos e transferências fez com que a renda das famílias e das ISL representasse conjuntamente $64 \%$ da oferta ou demanda totais em 2016. O governo vem em seguida, com 14\%, acompanhado de perto pelo resto do mundo (12,5\%) e, por último, vem o setor empresarial, com $9,5 \%$.

Para obter o saldo financeiro de cada setor institucional, é necessário subtrair os gastos da renda final e adicionar as transações de capital. A Tabela 4 detalha as etapas desse processo. Em contraste com o caso dos Estados Unidos, descrito por Barbosa-Filho (2018), no Brasil fez-se necessário realizar um ajuste no cálculo da poupança dos agentes devido à existência de mecanismos de "poupança forçada", isto é, acumulação de ativos financeiros por parte das famílias, mas que não estavam imediatamente disponíveis para consumo e investimento. Este ajuste aparece na linha "ajuste de fundos de poupança" na tabela 4 e corresponde ao saldo líquido de depósitos em contas do fundo de garantia do tempo de serviços (FGTS), programa de integração social (PIS) e programa de formação do patrimônio do servidor público (PASEP). Como estas contas são administradas pelo governo e pelo setor financeiro, a contrapartida da acumulação forçada de ativos pelas famílias constitui uma "emissão" por parte do governo e empresas financeiras. 
Tabela 4 - Brasil, 2016, renda final, demanda final e saldo financeiro por setor institucional em milhões de reais, recebimentos (+) ou pagamentos (-)

\begin{tabular}{|c|c|c|c|c|c|c|c|}
\hline & FAM & EMP & FIN & GOV & ISL & RDM & Total \\
\hline $\begin{array}{l}\text { 1) Valor adicionado } \\
\text { PM + importações }\end{array}$ & 1.142.389 & 2.798.175 & 416.253 & 1.855 .333 & 55.055 & 756.520 & 7.023.725 \\
\hline $\begin{array}{l}\text { 2) Realocação da } \\
\text { renda do trabalho }\end{array}$ & 2.669 .981 & -1.614 .413 & -156.672 & -847.005 & -50.884 & -1.007 & $\mathbf{0}$ \\
\hline $\begin{array}{l}\text { 3) Realocação da } \\
\text { renda de propriedade }\end{array}$ & 526.579 & -387.887 & -44.499 & -232.948 & 7.035 & 131.720 & $\mathbf{0}$ \\
\hline $\begin{array}{l}\text { 4) Renda Nacional } \\
\text { Bruta + Importações } \\
(1+2+3)\end{array}$ & 4.338.949 & 795.875 & 215.082 & 775.380 & 11.206 & 887.233 & 7.023.725 \\
\hline $\begin{array}{l}\text { 5) Impostos, } \\
\text { Contribuições e } \\
\text { Transferências }\end{array}$ & 65.016 & -328.299 & -13.732 & 205.856 & 80.339 & -9.180 & $\mathbf{0}$ \\
\hline $\begin{array}{l}\text { 6) Renda Disponível } \\
\text { Bruta + Importações } \\
(4+5)\end{array}$ & 4.403 .965 & 467.576 & 201.350 & 981.236 & 91.545 & 878.053 & 7.023.725 \\
\hline $\begin{array}{l}\text { 7) Consumo, Ajustes } \\
\text { e Exportações }\end{array}$ & -3.871 .186 & $\mathbf{0}$ & -31.880 & -1.311 .664 & -88.928 & -781.577 & -6.085 .235 \\
\hline Menos consumo final & -3.937 .085 & & & -1.277 .645 & -88.928 & & -5.303 .658 \\
\hline $\begin{array}{l}\text { Ajuste de fundos de } \\
\text { poupança }\end{array}$ & 65.899 & & -31.880 & -34.019 & & & 0 \\
\hline Menos exportações & & & & & & -781.577 & -781.577 \\
\hline $\begin{array}{l}\text { 8) Poupança Total } \\
(6+7)\end{array}$ & 532.779 & 467.576 & 169.470 & -330.428 & 2.617 & 96.476 & 938.490 \\
\hline $\begin{array}{l}\text { 9) Formação Bruta de } \\
\text { Capital }\end{array}$ & -361.645 & -442.889 & -7.590 & -121.248 & -5.118 & $\mathbf{0}$ & -938.490 \\
\hline $\begin{array}{l}\text { Formação Bruta de } \\
\text { Capital Fixo }\end{array}$ & -361.645 & -477.670 & -7.590 & -121.248 & -5.118 & & -973.271 \\
\hline Variação de Estoques & & 34.781 & & & & & 34.781 \\
\hline $\begin{array}{l}\text { 10) Saldo Corrente } \\
(8+9)\end{array}$ & 171.134 & 24.687 & 161.880 & -451.676 & -2.501 & 96.476 & $\mathbf{0}$ \\
\hline $\begin{array}{l}\text { 11) Transferências de } \\
\text { capital }\end{array}$ & -713 & -4.016 & -463 & 3.291 & 2.856 & -955 & $\mathbf{0}$ \\
\hline $\begin{array}{l}\text { Ativos não financeiros } \\
\text { não produzidos }\end{array}$ & & -2.766 & & 3.450 & & -684 & 0 \\
\hline $\begin{array}{l}\text { Transferências de } \\
\text { capital a receber }\end{array}$ & 7.046 & 484 & & 32.561 & 2.856 & 266 & 43.213 \\
\hline $\begin{array}{l}\text { Transferências de } \\
\text { capital a pagar }\end{array}$ & -7.759 & -1.734 & -463 & -32.720 & & -537 & -43.213 \\
\hline $\begin{array}{l}\text { 12) Saldo Financeiro } \\
(10+11)\end{array}$ & 170.421 & 20.671 & 161.417 & -448.385 & 355 & 95.521 & $\mathbf{0}$ \\
\hline
\end{tabular}

Fonte: Contas Econômicas Integradas (2016). Elaboração dos autores. 
As famílias (inclusive ISL), que tinham uma renda disponível bruta de $\mathrm{R} \$$ 4,5 trilhões, gastaram $\mathrm{R} \$ 4,3$ trilhões (com o consumo de $\mathrm{R} \$ 3,96$ trilhões, o investimento de $\mathrm{R} \$ 366,8$ bilhões e o recebimento de transferência de capital de $\mathrm{R} \$ 2,1$ bilhões) e terminaram com um saldo financeiro positivo de $\mathrm{R} \$ 170,8$ bilhões. O setor empresarial, após realizar um investimento de $\mathrm{R} \$ 450,5$ bilhões e ter pago $\mathrm{R} \$ 4,5$ bilhões em transferência de capital, além de um ajuste de fundos de poupança de $\mathrm{R} \$ 31,9$ bilhões por parte do setor financeiro, obteve um saldo financeiro positivo de $\mathrm{R} \$ 182,1$ bilhões. O resto do mundo demandou $\mathrm{R} \$ 781,6$ bilhões em exportações do Brasil em 2016 e pagou ao país R 955 milhões em transferências de capital. Como tinha recursos no valor de R 878,1 bilhões, provenientes de importações e transferências de renda, seu saldo financeiro foi positivo em $\mathrm{R} \$ 95,5$ bilhões.

A contraparte do superávit de todos esses setores institucionais foi o déficit financeiro de $\mathrm{R} \$ 448,4$ bilhões do governo, que detinha uma renda disponível de $\mathrm{R} \$$ 981,2 bilhões e teve consumo de $\mathrm{R} \$ 1,3$ trilhão, investimento de $\mathrm{R} \$ 121,3$ bilhões e recebeu transferência de capital de $\mathrm{R} \$ 3,3$ bilhões.

\section{Matriz de fluxo de fundos e de ativos financeiros líquidos}

O saldo financeiro apresentado na Tabela 4 corresponde à capacidade ou necessidade líquida de financiamento de cada setor e é igual à sua aquisição líquida de ativos financeiros. A Tabela 5 mostra a alocação do saldo financeiro dos setores institucionais entre vários instrumentos financeiros. Como o IBGE consolida os dados de famílias e instituições sem fins lucrativos para as contas de ativos, as próximas tabelas mostrarão cinco setores institucionais e não mais seis, como anteriormente.

Por se tratar de aquisições líquidas de ativos financeiros, o total das operações por instrumento financeiro (total das linhas) será igual a zero, com exceção dos ativos ouro monetário e outras contas, que apresentam pequenas discrepâncias nos dados do IBGE. 
Tabela 5 - Brasil, 2016, Fluxo de fundos em milhões de reais, credor (+) ou devedor (-)

\begin{tabular}{lcccccc}
\hline & FAM+ISL & EMP & FIN & GOV & RDM & Total \\
\hline $\begin{array}{l}\text { 1) Aquisição líquida de ativos } \\
\text { financeiros }\end{array}$ & $\mathbf{1 7 0 . 7 7 6}$ & $\mathbf{2 0 . 6 7 1}$ & $\mathbf{1 6 1 . 4 1 7}$ & $\mathbf{- 4 4 8 . 3 8 5}$ & $\mathbf{9 5 . 5 2 1}$ & $\mathbf{0}$ \\
$\quad$ & & & -152 & & -39 & -190 \\
Ouro monetário e DES & 97.806 & -28.297 & -141.489 & 85.951 & -13.971 & 0 \\
Numerário e depósitos & 34.526 & 93.932 & 510.807 & -515.968 & -123.296 & 0 \\
Títulos de dívidas & -74.772 & 60.372 & 4.130 & -52.523 & 62.793 & 0 \\
$\begin{array}{l}\text { Empréstimos } \\
\text { Participações de capital e em }\end{array}$ & 237.993 & -188.346 & -265.087 & 16.607 & 198.832 & 0 \\
$\begin{array}{l}\text { fundos de investimentos } \\
\text { Sistemas de seguros, de previdência }\end{array}$ & 102.817 & 476 & -103.293 & & & 0 \\
$\begin{array}{l}\text { e regime de garantias padronizadas } \\
\text { Derivativos financeiros }\end{array}$ & -6.424 & -34.427 & 39.009 & & 1.842 & 0 \\
Outras contas a receber/pagar & -221.170 & 116.962 & 117.492 & 17.548 & -30.640 & 190 \\
\hline
\end{tabular}

Fonte: Contas Econômicas Integradas (2016). Elaboração dos autores.

Toda operação de crédito tem sua contraparte em uma operação de débito. Conforme pode ser observado na Tabela 5, o governo foi o único setor institucional com necessidade líquida de financiamento em 2016 e, portanto, todos os outros setores foram seus credores. As famílias supriram R \$ 170,8 bilhões dos R \$ 448,4 bilhões necessários para o financiamento do governo, ou 38,1\% do montante. As empresas financeiras forneceram $36 \%$ dos recursos. O resto do mundo e as empresas não financeiras completaram o financiamento com 21,3\% e 4,6\% dos recursos, respectivamente.

Analisando a coluna referente ao governo, pode-se verificar com que instrumentos ele se financiou. O governo aumentou sua posse de numerário e depósitos em $\mathrm{R} \$ 86$ bilhões e suas participações de capital e em fundos de investimentos em $\mathrm{R} \$ 16,6$ bilhões, além de ter recebido $\mathrm{R} \$ 17,6$ bilhões de outras contas. Por outro lado, seu déficit foi financiado por meio da tomada de R $\$ 52,5$ bilhões de empréstimos e, principalmente, por meio da emissão de títulos de dívidas no valor de $\mathrm{R} \$ 516$ bilhões, que foram adquiridos, em grande parte, pelas empresas financeiras. $\mathrm{O}$ resto do mundo também foi um grande emissor de títulos de dívidas, no valor de $\mathrm{R} \$ 123,3$ bilhões, que foram adquiridos pelas famílias e pelas empresas não financeiras, além das empresas financeiras.

Outro instrumento que movimentou muitos recursos líquidos entre os setores institucionais foi o de participações de capital e em fundos de investimentos. As famílias e o resto do mundo aumentaram suas participações nas 
empresas financeiras e não financeiras em um montante de $\mathrm{R} \$ 238$ bilhões e $\mathrm{R} \$$ 198,8 bilhões, respectivamente.

Tabela 6 - Brasil, 2016, Variação de ativos financeiros líquidos em milhões de reais

\begin{tabular}{|c|c|c|c|c|c|c|}
\hline & FAM+ISL & EMP & FIN & GOV & RDM & Total \\
\hline $\begin{array}{l}\text { 1) Aquisição líquida de ativos } \\
\text { financeiros }\end{array}$ & 170.776 & 20.671 & 161.417 & -448.385 & 95.521 & $\mathbf{0}$ \\
\hline $\begin{array}{l}\text { 2) Variação de ativos } \\
\text { financeiros líquidos }\end{array}$ & 496.257 & -17.049 & -81.116 & -875.590 & 476.739 & -758 \\
\hline Ouro monetário e DES & & & -454 & & -303 & -758 \\
\hline Numerário e depósitos & 78.347 & -43.891 & -221.096 & 128.516 & 58.124 & 0 \\
\hline Títulos de dívidas & 34.502 & 117.821 & 572.182 & -821.059 & 96.554 & 0 \\
\hline Empréstimos & -49.584 & 226.591 & 36.901 & -35.849 & -178.059 & 0 \\
\hline $\begin{array}{l}\text { Participações de capital e em } \\
\text { fundos de investimentos }\end{array}$ & 282.713 & -445.670 & -553.056 & 132.203 & 583.810 & 0 \\
\hline $\begin{array}{l}\text { Sistemas de seguros, de } \\
\text { previdência e regime de } \\
\text { garantias padronizadas }\end{array}$ & 195.161 & 476 & -195.636 & & & 0 \\
\hline Derivativos financeiros & -593 & -1.516 & 50.181 & & -48.073 & 0 \\
\hline Outras contas a receber/pagar & -44.289 & 129.140 & 229.863 & -279.400 & -35.314 & 0 \\
\hline
\end{tabular}

Fonte: Contas Econômicas Integradas (2016). Elaboração dos autores.

As tabelas de alocações de ativos do IBGE apresentadas nas Contas Econômicas Integradas podem ser utilizadas para se deduzir as variações dos ativos financeiros líquidos. Como pode ser visto na Tabela 6, esses valores são distintos da aquisição líquida de ativos financeiros apresentada na Tabela 5, pois as variações dos ativos financeiros incorporam o ganho ou perda de capital.

Subtraindo a aquisição líquida de ativos financeiros da variação de ativos financeiros líquidos, tem-se os ganhos de capital por instrumentos financeiros, mostrados na Tabela 7. As variações dos ativos devidas aos ganhos ou perdas de capital são substantivas. O aumento de $\mathrm{R} \$ 496,3$ bilhões de ativos das famílias, por exemplo, foi devido, em grande parte, ao seu ganho de capital de $\mathrm{R} \$ 325,5$ bilhões, provindo principalmente da valorização de outras contas, sistemas de seguros e previdência e participações de capital e em fundos de investimentos. Diante do montante de ganho de capital, o saldo financeiro das famílias, de $\mathrm{R} \$ 170,8$ bilhões, contribuiu relativamente pouco para a variação de sua riqueza financeira. 
Tabela 7 - Brasil, 2016, Ganho de capital em milhões de reais

\begin{tabular}{|c|c|c|c|c|c|c|}
\hline & FAM+ISL & EMP & FIN & GOV & RDM & Total \\
\hline $\begin{array}{l}\text { 1) Aquisição líquida de } \\
\text { ativos financeiros }\end{array}$ & 170.776 & 20.671 & 161.417 & -448.385 & 95.521 & $\mathbf{0}$ \\
\hline $\begin{array}{l}\text { 2) Variação de ativos } \\
\text { financeiros líquidos }\end{array}$ & 496.257 & -17.049 & -81.116 & -875.590 & 476.739 & -758 \\
\hline 3) Ganho de capital (3-1) & 325.481 & -37.720 & -242.533 & -427.205 & 381.218 & -758 \\
\hline Ouro monetário e DES & & & -303 & & -265 & -567 \\
\hline Numerário e depósitos & -19.460 & -15.594 & -79.607 & 42.565 & 72.095 & 0 \\
\hline Títulos de dívidas & -24 & 23.889 & 61.375 & -305.091 & 219.850 & 0 \\
\hline Empréstimos & 25.188 & 166.220 & 32.770 & 16.673 & -240.852 & 0 \\
\hline $\begin{array}{l}\text { Participações de capital e } \\
\text { em fundos de } \\
\text { investimentos }\end{array}$ & 44.720 & -257.324 & -287.970 & 115.596 & 384.978 & 0 \\
\hline $\begin{array}{l}\text { Sistemas de seguros, de } \\
\text { previdência e regime de } \\
\text { garantias padronizadas }\end{array}$ & 92.344 & 0 & -92.344 & & & 0 \\
\hline Derivativos financeiros & 5.832 & 32.911 & 11.172 & & -49.915 & 0 \\
\hline $\begin{array}{l}\text { Outras contas a } \\
\text { receber/pagar }\end{array}$ & 176.881 & 12.179 & 112.372 & -296.948 & -4.674 & -190 \\
\hline
\end{tabular}

Fonte: Contas Econômicas Integradas (2016). Elaboração dos autores.

As empresas financeiras e não financeiras, que tinham saldos financeiros positivos, por conta de perdas de capital da ordem de $\mathrm{R} \$ 242,5$ bilhões e $\mathrm{R} \$ 37,7$ bilhões, respectivamente, registraram diminuição de seus ativos financeiros líquidos.

O governo, que apresentava uma necessidade de financiamento de $\mathrm{R} \$ 448,4$ bilhões, quase dobrou essa cifra, por conta de uma perda de capital de $\mathrm{R} \$ 427,2$ bilhões, devida a perdas de capital de $\mathrm{R} \$ 305,1$ bilhões em títulos de dívidas e $\mathrm{R} \$$ 297 bilhões em outras contas a receber/pagar, parcialmente compensadas por ganhos de capital de numerário e depósitos, empréstimos e participações de capital e em fundos de investimentos.

$\mathrm{O}$ resto do mundo, que tinha um saldo financeiro relativamente modesto, obtém uma grande variação positiva de seus ativos financeiros líquidos devido a um ganho de capital de $\mathrm{R} \$ 381,2$ bilhões. O ganho com títulos de dívidas e participações de capital e em fundos de investimentos foram os principais responsáveis por esse resultado, parcialmente contrabalançado por uma perda de capital expressiva de empréstimos, de $\mathrm{R}$ \$240,9 bilhões.

Alguns estudos apontam que movimentos de ganhos ou perdas de capital têm aumentado sua importância na determinação da dinâmica da riqueza financeira nas últimas décadas (Roth, 2016). Os dados da Matriz de Contabilidade Social 
Vertical corroboram essa afirmação. O comportamento dos ganhos de capital é essencial para compreender a dinâmica da dívida líquida dos setores institucionais.

\section{Resultado primário e pagamento de juros dos setores institucionais}

Nas seções anteriores, foram apresentados os dados da matriz de contabilidade social para o ano de 2016. Com base nas estimativas elaboradas pelo IBGE, é possível fazer o mesmo para os fluxos desde 2000 e, para os estoques, desde 2009. Nesta seção, os conceitos detalhados nas seções anteriores serão utilizados para analisar o resultado financeiro dos setores institucionais e sua desagregação entre resultado primário e pagamento de juros.

O primeiro passo consiste em apresentar a evolução do resultado financeiro dos principais setores institucionais. Para simplificar a exposição, os dados das famílias e das instituições sem fins lucrativos serão consolidados em um único setor. A Figura 1 traz a série histórica entre 2000 e 2016. Todos os valores são expressos em \% do PIB brasileiro, e os principais fatos estilizados são os seguintes:

i) $\mathrm{O}$ resto do mundo passou de um elevado superávit em 2000-01, da ordem de 5\% do PIB, para um pequeno déficit em 2004-06. A taxa de câmbio efetiva real em patamares relativamente elevados entre 2000 e 2004, conjugada ao início de um boom de preços de commodities já ao final de 2003, provavelmente esteve associada à intensa elevação das exportações brasileiras simultaneamente a um aumento moderado das importações no início da década de 2000. Esses dois movimentos resultaram na forte retração da posição superavitária do resto do mundo ressaltada anteriormente (culminando em um deficit em 2004-06). Apesar da intensificação do boom de preços de commodities até a crise financeira mundial de 2008, a apreciação do câmbio real ocorrida entre 2005 e 2011 contribuiu para acelerar a absorção doméstica, e o setor externo voltou a registrar superávits a partir de 2007. Em 2014, o superávit financeiro do resto do mundo com o Brasil atingiu 4,5\% do PIB. Nos anos seguintes, este valor se reduziu devido à recessão da economia brasileira de 2015-16;

ii) As famílias brasileiras registraram superávit financeiro ligeiramente superior a $2 \%$ do PIB de 2000 a 2005. A partir de 2006, com o aumento do acesso ao crédito, o superávit das famílias caiu gradualmente, até atingir o mínimo de $0,6 \%$ do PIB em 2014. A recessão de 2015-16 foi acompanhada por forte ajuste no orçamento familiar, o que elevou o superávit para 2,7\% do PIB em apenas dois anos; 
iii) O setor financeiro foi superavitário ao longo de todo o período em análise, com saldos positivos superiores a $2 \%$ do PIB durante a maior parte do tempo. O valor máximo foi atingido em 2007 , de 5,2\% do PIB. No período mais recente, o saldo positivo do sistema financeiro se estabilizou em 2\% do PIB, mesmo no contexto de recessão de 2015-16;

iv) As empresas não financeiras tinham elevado déficit em 2000-01, da ordem de 4\% do PIB. O forte aumento da renda disponível das empresas entre 2001-2003 e a redução dos investimentos em quase um ponto percentual do PIB no mesmo período fizeram com que o déficit se reduzisse rapidamente. A posição das empresas não financeiras permaneceu relativamente estável até 2006. A partir de 2007, com a aceleração do crescimento e do investimento, o déficit voltou a subir, ficando próximo de 4\% do PIB até 2011. O quadro mudou a partir da reversão do superciclo internacional de commodities em 2012, quando as empresas brasileiras iniciaram um processo de redução de posições deficitárias. A maior parte do ajuste ocorreu entre 2012 e 2015, com o setor registrando um pequeno superávit financeiro ao final do período;

v) O governo foi o setor tradicionalmente deficitário durante o período em análise. O déficit chegou a ser superior a $6 \%$ do PIB no início dos anos 2000. A elevação do resultado primário durante o início do governo do presidente Luiz Inácio Lula da Silva condicionou uma redução para o patamar de 4\% do PIB em 2004-09. O boom dos preços das commodities e a redução da taxa real de juros estabeleceram as condições para que o déficit do governo se reduzisse mais nos anos seguintes, chegando a 2,3\% do PIB em 2012. A partir de então, a mudança no cenário internacional e a combinação de desaceleração do crescimento com elevação da taxa de juros real pressionaram o déficit do governo para quase 8\% do PIB em 2015, com pequena redução em 2016. 


\section{Figura 1 - Resultado financeiro por setor institucional em \% do PIB (Brasil,} 2000-2016)

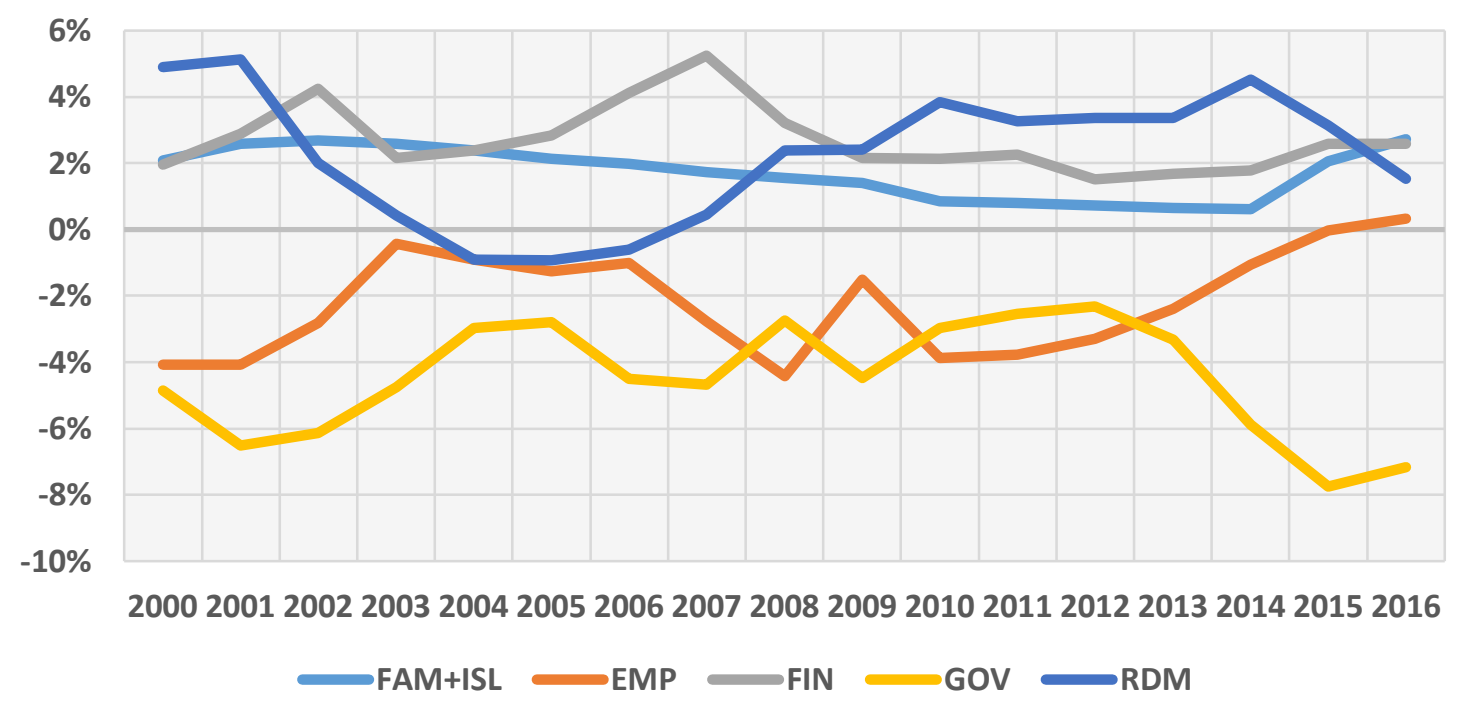

Fonte: Contas Econômicas Integradas (2016). Elaboração dos autores.

A respeito do item (iv), o financiamento privado das atividades de empresas não financeiras é historicamente incipiente no Brasil, mas passou por grandes transformações ao longo do período analisado. Mesmo com o fim do período inflacionário, a ausência de um mercado financeiro de longo prazo amadurecido foi um traço da economia brasileira que se manteve durante os anos posteriores ao Plano Real. Diante das outras opções de ativos financeiros, em especial os títulos públicos, que ofereciam alta rentabilidade e segurança, o mercado de dívida corporativa se desenvolveu relativamente pouco na década de 2000, com forte dominância do crédito bancário (Carvalho, 2017; Torres Filho e Macahyba, 2012).

Contudo, mudanças institucionais e macroeconômicas estimularam o aumento do financiamento privado, em particular, no que diz respeito ao mercado de debêntures. As debêntures de infraestrutura, ou debêntures incentivadas, instituídas pela Lei $\mathrm{n}^{\circ} 12.431$ de 2011, foram um marco institucional importante para o mercado doméstico privado de financiamento de longo prazo (Bragança, Pessoa e Souza, 2015). Com o intuito de incentivar o financiamento de infraestrutura, essa modalidade de título de crédito contou com isenções tributárias e passou a responder por uma parcela significativa dos investimentos nesse setor. Rocca (2018) afirma que as debêntures de infraestrutura corresponderam a 17,2\% dos recursos de todos os projetos vinculados a essas emissões aprovados até 2018. 
O crescimento das debêntures "comuns" ou incentivadas, no entanto, não causou grande impacto na composição do passivo das empresas não financeiras, como mostrado na Figura 2. As debêntures são classificadas nas Contas Nacionais no item Títulos de dívidas, que, apesar de ter ganho importância desde 2009, ainda é relativamente pequeno na estrutura do passivo, muito concentrado em participações de capital e em fundos de investimentos, empréstimos e outras contas a pagar, que compreendem créditos comerciais e adiantamentos.

Contudo, os dados da Figura 2 requerem uma interpretação cautelosa por conta de características institucionais do mercado de debêntures. Como apontado por Carvalho (2017), a instrução 476 da Comissão de Valores Mobiliários (CVM), de 2009, incentivou o crescimento de emissões de debêntures, mas também gerou um mercado dual, com alta intermediação financeira, operando parte como mercado de capitais, parte como mercado de crédito. A forma como essa dualidade é incorporada na estrutura de passivos nas Contas Nacionais requer maiores investigações.

Figura 2 - Composição do passivo das empresas não financeiras

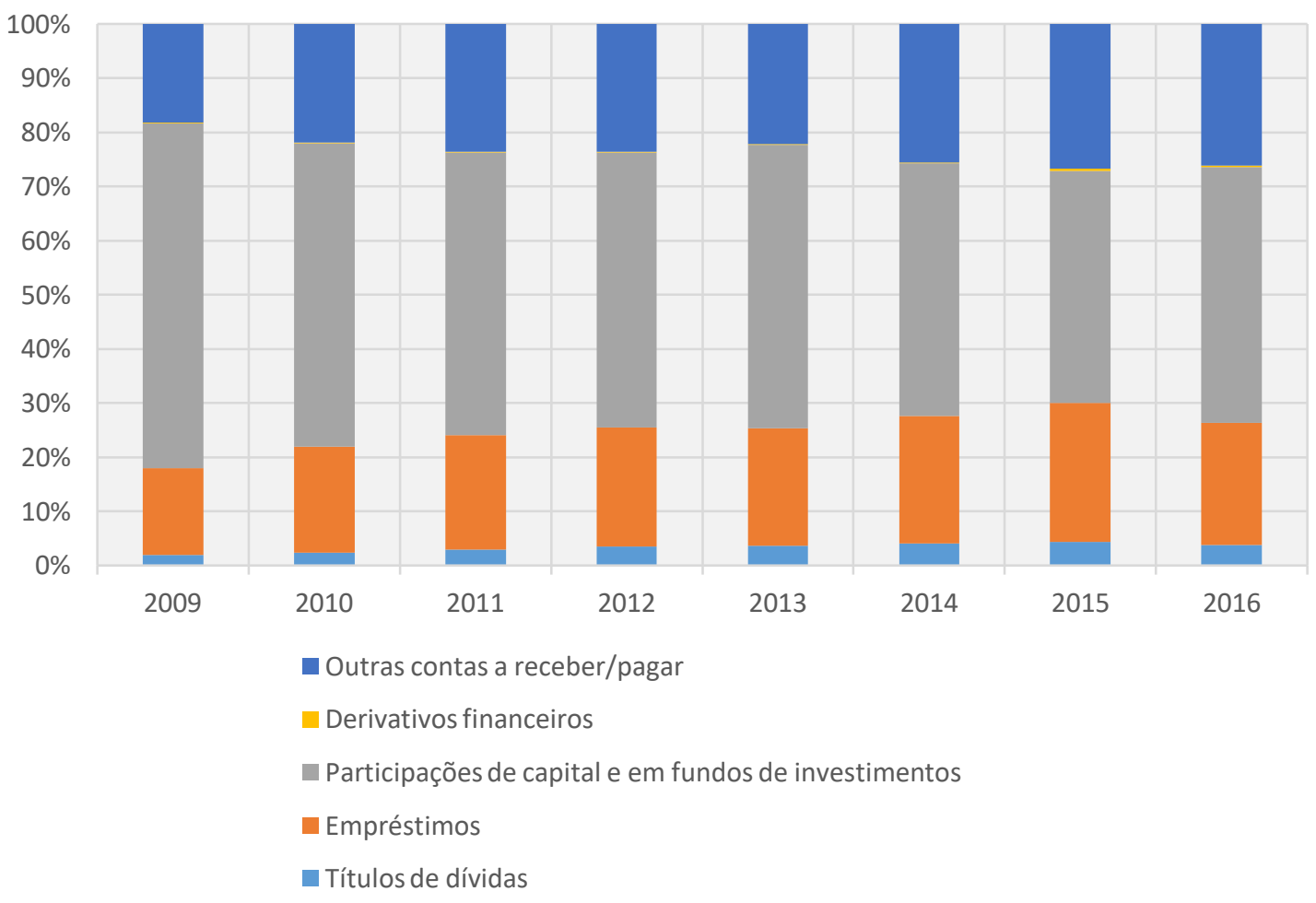

Fonte: Contas Econômicas Integradas (2016). Elaboração dos autores. 
Os dados apresentados na Figura 1 incluem o pagamento líquido de juros. Para se obter os resultados primários de cada agente, é preciso efetuar a dedução dos juros dos resultados financeiros apresentados anteriormente ${ }^{4}$. Os pagamentos de juros por setor institucional (Figura 3) revelam que:

i) Entre 2000 e 2005 as empresas não financeiras foram pagadoras líquidas de juros. A partir de 2006, o resultado tem sido de relativo equilíbrio, isto é, pagamento de juros líquidos próximos a zero em \% do PIB;

ii) O governo é o grande pagador de juros líquidos no Brasil. O valor total flutuou em torno de 6\% do PIB entre 2000 e 2006. Posteriormente, com a aceleração do crescimento do PIB e redução da taxa real de juros, o pagamento de juros sobre a dívida líquida do governo caiu progressivamente para o patamar de 4,4\% do PIB, entre 2007 e 2014 . A intensa elevação da taxa básica de juros no primeiro semestre de 2015 elevou a despesa com juros do governo naquele ano para 6,3\% do PIB. Em 2016, contudo, o pagamento voltou a cair, para 4,6\% do PIB.

\section{Figura 3 - Juros recebidos por setor institucional em \% do PIB (Brasil, 2000-2016)}

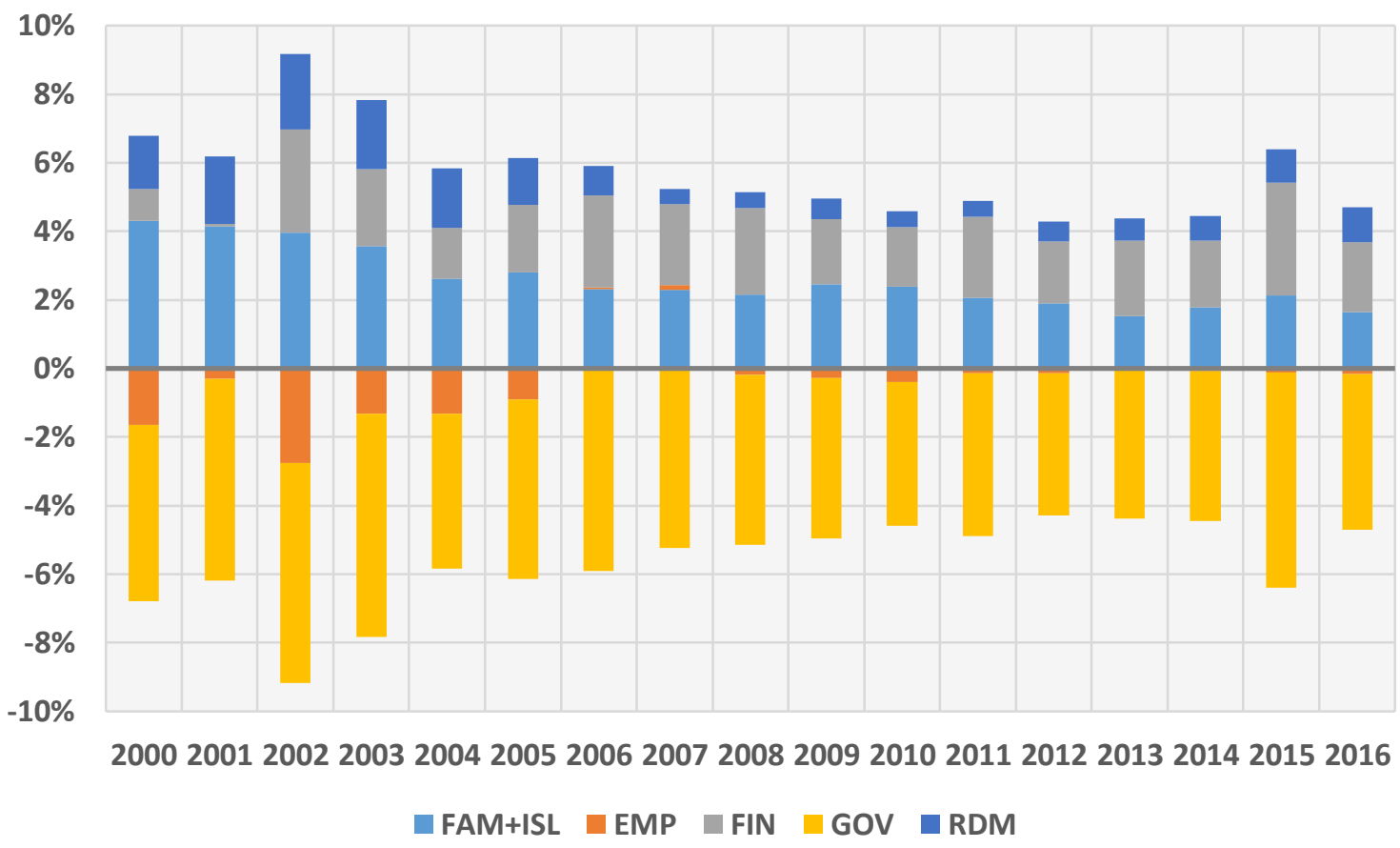

Fonte: Contas Econômicas Integradas (2016). Elaboração dos autores.

\footnotetext{
${ }^{4}$ Em nosso exemplo do ano de 2016, os resultados primários dos setores institucionais são obtidos subtraindo-se os juros (subitem da realocação da renda de propriedade apresentado na Tabela 2) do saldo financeiro da Tabela 4.
} 
A Figura 4 apresenta o resultado primário de cada setor institucional ${ }^{5}$. Para se ter um vislumbre mais claro do comportamento do resultado primário no período, os dados apresentados na Figura 4 são desagregados em três setores: governo e resto do mundo, tais como expostos anteriormente, e privado (PRI), conjunto dos setores famílias, instituições sem fins lucrativos e instituições financeiras e não financeiras. Os movimentos mais gerais são descritos a seguir:

i) O setor privado, que apresentava um elevado déficit primário em 200001, em torno de $3 \%$ do PIB, passou por forte ajuste no início da década de 2000 e permaneceu com um resultado primário próximo de zero até 2006. A partir de 2007, com o aquecimento da economia, um boom de preços de commodities, o aumento dos investimentos públicos e privados, a elevação do salário mínimo em termos reais e a expansão dos programas de transferência de renda, o setor privado iniciou um intenso processo de aumento de déficits (brevemente interrompido pelos impactos da crise financeira internacional em 2009), que se estende até 2011, quando seu déficit primário atinge 5\% do PIB. Com a reversão cíclica dos preços das commodities iniciada em 2012 e a redução do crescimento econômico, o setor privado passou a contrair fortemente suas posições deficitárias, intensificando essa tendência com a recessão de 2015-16, chegando a um superávit primário de 2,1\% do PIB no último ano;

ii) O resto do mundo, que era superavitário em 2000-01, passou a registrar déficits de 2002 em diante, chegando a 2,7\% do PIB em 2004. A partir daí, diminuiu progressivamente sua posição deficitária e voltou a ser superavitário em 2008, permanecendo com um resultado positivo em torno de $3 \%$ do PIB entre 2010 e 2014 . A depreciação deflagrada em 2015 impactou fortemente o resultado do resto do mundo, fazendo com que seu superávit fosse reduzido até $0,5 \%$ do PIB em 2016;

iii) O governo, que tinha um pequeno déficit primário, de $0,6 \%$ do PIB em 2001, passou a apresentar seguidos superávits primários a partir de 2003, oscilando entre $1 \%$ e $2 \%$ do PIB até 2013. Contudo, a partir do ano seguinte o cenário se altera: do superávit de 1,1\% do PIB em 2013, passa a um déficit de $1,5 \%$ do PIB no ano seguinte. A recessão de 2015 -

\footnotetext{
${ }^{5}$ Antes de prosseguir, cabe ressaltar que esta definição, baseada nas contas nacionais, difere do conceito de resultado primário apurado pelo Banco Central do Brasil (BCB) para o governo, porque, nas definições do IBGE, o resultado financeiro é calculado antes da aquisição ou emissão de ativos financeiros de renda variável. Em outras palavras, enquanto o BCB considera inversões financeiras como despesas em sua metodologia de caixa, o IBGE calcula o resultado financeiro com base na diferença entre poupança e investimento somente em capital fixo.
} 
16 agravou o quadro, e o déficit primário, que havia se mantido estável em 2015, elevou-se para 2,6\% do PIB em 2016.

É interessante notar que a necessidade de financiamento de um setor tem de ser compensada com a capacidade de financiamento de algum outro. Então, podese observar que o movimento de redução do déficit do setor privado e de expansão do superávit do setor governo verificado no início do período teve sua contraparte na transição do resto do mundo de uma posição superavitária para deficitária. Também pode-se verificar que a intensa posição deficitária do setor privado a partir de 2007 foi permitida pelos superávits apresentados pelo resto do mundo e pelo governo. Por fim, a forte reversão ocorrida em 2012, com intensa contração do déficit do setor privado, teve sua correspondência na pronunciada queda do superávit do resto do mundo, bem como na conversão dos resultados primários do governo de superávits para acentuados déficits.

\section{Figura 4 - Resultado primário por setores governo, privado e resto do mundo em \% do PIB (Brasil, 2000-2016)}

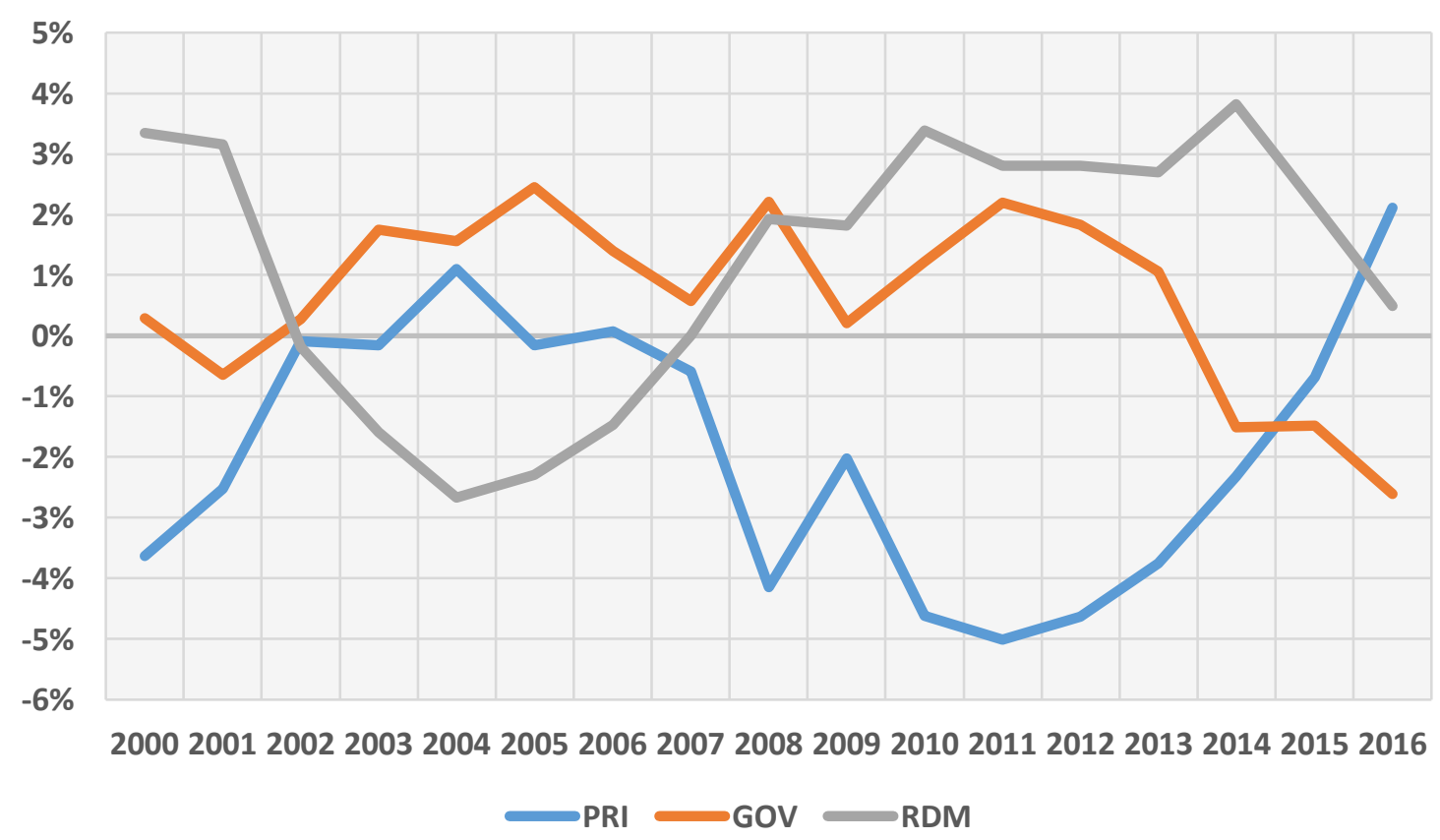

Fonte: Contas Econômicas Integradas, 2016. Elaboração dos autores.

A Figura 5 traz mais detalhes sobre o comportamento do setor privado ao desagregá-lo nos três setores exibidos anteriormente. Observa-se que o déficit primário do setor privado em 2000-01 (Figura 4) estava associado às posições 
deficitárias das famílias e empresas não financeiras, parcialmente compensado pelo superávit do setor financeiro. A estabilização do resultado primário do setor privado em torno de zero entre 2002 e 2007 decorreu do intenso ajuste das empresas não financeiras, que apresentaram superávit em 2003-04, e pela redução do déficit das famílias. De modo similar, o processo de expansão do déficit em 2007-11 se deu com o aumento dos déficits das empresas não financeiras entre 2006 e 2011, seguido pelas famílias, que elevaram seu déficit primário para 1,5\% do PIB em 2010. O processo de ajuste de 2012-16 também se iniciou com as empresas não financeiras e somente foi complementado pelas famílias quando as mesmas sofreram os efeitos da recessão de 2015-16.

\section{Figura 5 - Resultado primário por setor institucional em \% do PIB}

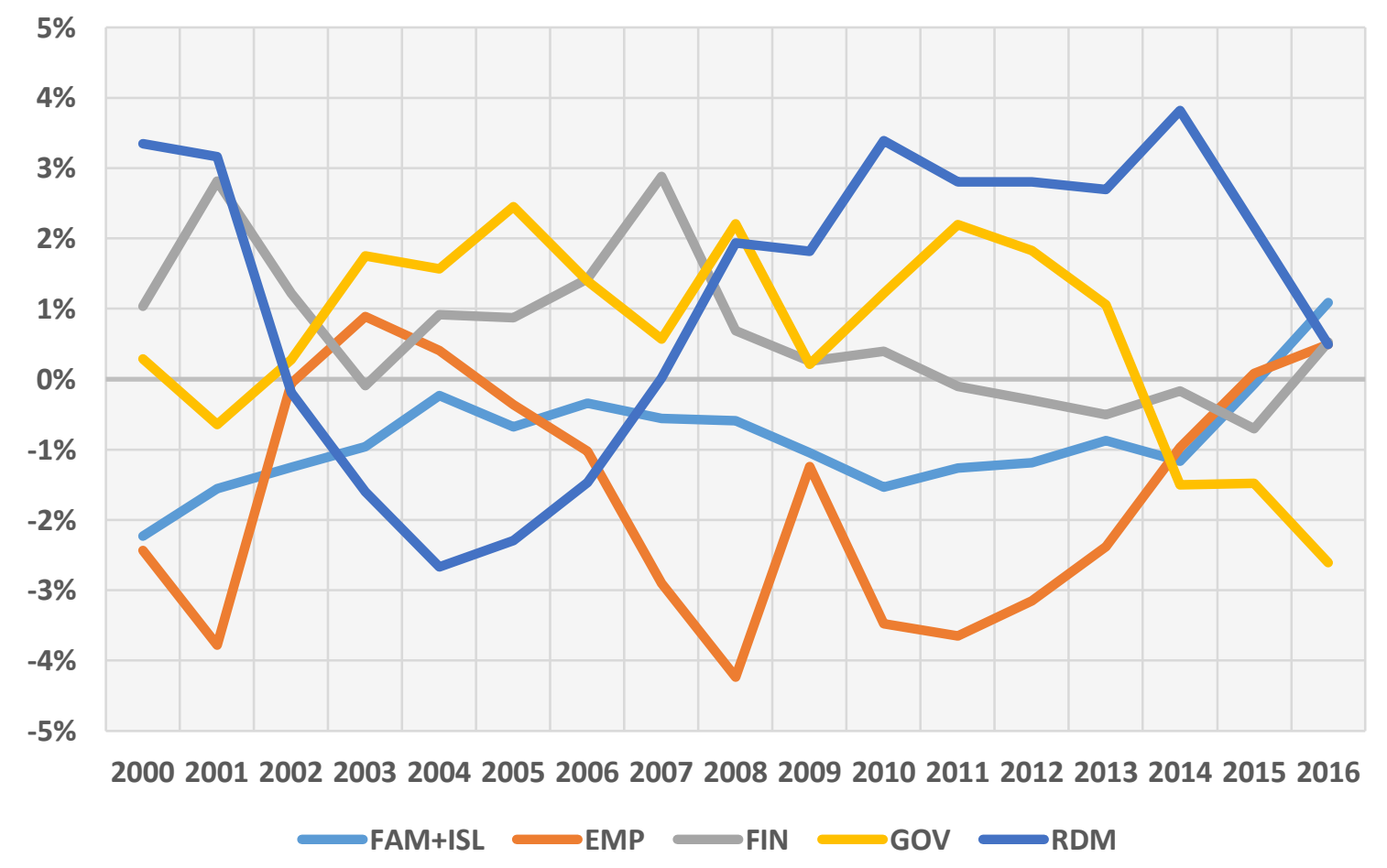

Fonte: Contas Econômicas Integradas, 2016. Elaboração dos autores.

Com o quadro completo, pode-se compreender melhor a interação entre o resultado primário, o pagamento de juros e o resultado financeiro para cada setor institucional. As famílias, por exemplo, que, exceto em 2016, apresentaram déficit primário em todo o período estudado, por receberem uma parte expressiva dos juros, exibiram superávit financeiro ao longo de todos os anos analisados. $\mathrm{O}$ reverso ocorreu com o governo, que, apesar de ter alcançado superávits primários 
da ordem de $2 \%$ do PIB em alguns anos, por ser o principal pagador líquido de juros, manteve-se deficitário ao longo de todo o período.

\section{Conclusão}

Este trabalho apresenta a SAM vertical do Brasil conforme a metodologia proposta por Barbosa-Filho (2018). A partir desta organização dos dados das CEI publicadas pelo IBGE, é possível analisar a composição sequencial da renda, da produção à demanda, bem como a distribuição dos desequilíbrios correntes e a acumulação de ativos financeiros líquidos por setor institucional.

Assim, pode-se examinar a geração e distribuição da renda entre famílias, empresas, governo e setor externo durante o processo de produção, como ela é redistribuída com a realocação das rendas do trabalho e da propriedade, até se chegar à renda disponível para os agentes econômicos, etapa final do processo de realocação, após o balanço entre pagamento de impostos e contribuições para o governo, de um lado, e o recebimento de benefícios sociais pelas famílias, de outro, além do recebimento de outras transferências líquidas pelos setores institucionais.

O saldo corrente de cada setor institucional constitui o balanço entre sua renda disponível e seu consumo (ou exportações, no caso do resto mundo) e investimento. Ao adicionar-se as transferências de capital aos respectivos saldos correntes, obtém-se o saldo financeiro dos agentes institucionais.

Esses saldos são utilizados na aquisição líquida de ativos financeiros e demonstra o padrão de incorporação de fluxos aos estoques da economia, que, por sua vez, influenciará os ciclos posteriores. Essa proposta metodológica, portanto, provê um arcabouço simples para o desenvolvimento de uma agenda de trabalho em ensino e pesquisa de economia teórica e aplicada.

Em resumo, a análise da SAM vertical do Brasil mostrou que a economia brasileira está passando por uma intensa mudança das posições correntes dos setores institucionais, que se iniciou em 2012, intensificou-se com a recessão de 2015-16 e dá indícios de que ainda está em processo. Neste período, o setor privado passou por uma forte contração do déficit, tornando-se superavitário ao fim do período em que os dados estão disponíveis, enquanto o resto do mundo e o governo formaram a contraparte dessa tendência, mostrando uma queda expressiva dos superávits do primeiro e uma intensificação dos déficits do segundo. A atualização da SAM vertical para anos posteriores, a partir da disponibilidade de novos dados 
do IBGE, dará indícios mais claros sobre a direção desse processo e será uma das possibilidades de pesquisas futuras abertas por essa metodologia.

\section{Referências}

BARBOSA-FILHO, N. H. A vertical social accounting matrix of the U.S. economy. Journal of Post Keynesian Economics, v. 41, n. 4, p. 578-597, 2018.

BRAGANÇA, G. G.; PESSOA, M. DE S.; SOUZA, G. M. DE. Evolução recente do mercado de debêntures no Brasil: As debêntures incentivadas. 2015.

CARVALHO, P. S. DE. Perfil e determinantes do mercado de debêntures no Brasil no período 2004-2014. [s.1.] Universidade Federal do Rio de Janeiro, 2017.

GODLEY, W.; LAVOIE, M. Monetary economics: An integrated approach to credit, money, income, production and wealth. 2. ed. Houndmills, Basingstoke, Hampshire ; New York: Palgrave Macmillan UK, 2012.

IBGE. Sistema de Contas Nacionais do Brasil: Ano de referência 2010, $3^{a}$ edição: Série Relatórios Metodológicos. Rio de Janeiro: Instituto Brasileiro de Geografia e Estatística, 2016. Disponível em: <https://biblioteca.ibge.gov.br/index.php/bibliotec a-catalogo?view=detalhes\&id=298160>. Acesso em: 19 jun. 2018.

MACEDO E SILVA, A. C.; SANTOS, C. H. M. DOS. Um estudo da riqueza financeira do Brasil a partir da matriz de patrimônio financeiro do IBGE. Revista de Economia Contemporânea, v. 20, n. 2, p. 250-280, 2016.

ROCCA, C. A. Financiamento do investimento no Brasil e o papel do mercado de capitais. In: ALMEIDA, J. S. G. DE; CAGNIN, R. F. (Eds.). BNDES, mercado de capitais e o financiamento de longo prazo no Brasil. [s.1.] Instituto de Estudos para o Desenvolvimento Industrial, 2018.

ROTH, S. Why Economists Don't Know How to Think about Wealth (or Profits) Evonomics, 3 dez. 2016. Disponível em: <http://evonomics.com/economists-dontknow-think-wealth-profits/>. Acesso em: 20 jan. 2019.

SANTOS, C. H. M. DOS. Introdução. In: SANTOS, C. H. M. DOS (Ed.). Características estruturais do sistema financeiro brasileiro. Brasília, DF: Ipea, 2017. p. 9-13.

STONE, R.; BROWN, A. A computable model of economic growth. London: Chapman and Hall Ltd., 1962.

TAYLOR, L. Structuralist CGE models. In: TAYLOR, L. (Ed.). Socially Relevant Policy Analysis: Structuturalist Computable General Equilibrium Models for the Developing World. Cambridge: MIT Press, 1990. p. 1-70. 
TORRES FILHO, E. T.; MACAHYBA, L. O elo perdido: o mercado de títulos de dívida corporativa no Brasil: avaliação e propostas. São Paulo: IEDI, 2012. 